OPEN ACCESS

Edited by:

Subramaniam Ramanathan, Nanyang Technological University,

Singapore

Reviewed by:

Thomas K. F. Chiu,

University of Hong Kong, Hong Kong Taro Fujita,

University of Exeter, United Kingdom

*Correspondence:

Marina Milner-Bolotin marina.milner-bolotin@ubc.ca

Specialty section:

This article was submitted to

STEM Education,

a section of the journal

Frontiers in Education

Received: 26 April 2018

Accepted: 10 October 2018

Published: 02 November 2018

Citation:

Milner-Bolotin M (2018) Evidence-Based Research in STEM Teacher Education: From Theory to

Practice. Front. Educ. 3:92.

doi: 10.3389/feduc.2018.00092

\section{Evidence-Based Research in STEM Teacher Education: From Theory to Practice}

\author{
Marina Milner-Bolotin ${ }^{1,2 *}$ \\ ${ }^{1}$ Department of Curriculum and Pedagogy, University of British Columbia, Vancouver, BC, Canada, ${ }^{2}$ Advanced Innovation \\ Centre for Future Education, Beijing Normal University, Beijing, China
}

The paper identifies possible causes of STEM education reform failures and suggests how repairing the link between evidence-based education research and teacher education practice may address the problem. The evidence-based STEM education research is described and placed in the STEM teacher education context. The paper shows how this research may help reverse the growing student STEM disengagement, support effective learning environments, bring attention to teacher professional development, and inform STEM education policy. The paper calls on placing research-based STEM teacher education in the center of contemporary reform efforts and conducting evidence-based education research to study the effect of this process on the growth of teacher knowledge and subsequently on student learning. The major claim is that research-based teacher education and professional development are key factors in successful implementation of STEM education reforms. However, more research is needed to examine this assertion. We suggest a four-step approach for incorporating evidence-based education research and teacher education practice as a potential solution: Model-Reflect-Research-Practice. This approach emphasizes teacher-candidates' active engagement with research-based pedagogies as learners and as future teachers. It provides a universal framework for incorporating research-based pedagogies in teacher education as described in the two examples. The first example showcases Peer Instruction supported by PeerWise technology used to promote conceptual understanding through peer learning. The second example focuses on supporting teacher-candidates' growth by asking them to teach short mini-lessons, record and upload them onto the online collaborative platform (Collaborative Learning Annotation System) for peer feedback and reflection. Both examples incorporate collaborative educational technologies to promote the development of teacher-candidates' knowledge for STEM teaching and their growth mindset. The paper emphasizes how making evidence-based STEM education research a foundation of teacher education can help connect education research to teacher education practice and break the vicious circle of STEM education reform failures.

\footnotetext{
Keywords: evidence-based education research, growth mindset, Pedagogical Content Knowledge (PCK), teacher knowledge growth, STEM education, STEM teacher education, Technological Pedagogical and Content Knowledge (TPACK), Deliberate Pedagogical Thinking with Technology
} 


\section{INTRODUCTION}

"Those who fail to learn from history are doomed to repeat it". Sir Winston Churchill

Churchill's famous saying about human failure to learn from the past is still relevant today. However, we often forget that it applies not only to the history of civilizations, but also to the history of education reforms and their almost inevitable failure. As Cuban (1990) pointed out almost four decades ago, in order to solve this recurring problem we have to ask the right questions:

The return of school reforms suggests that the reforms have failed to remove the problems they were intended to solve. Analysts ask: Are we attacking the right problem? Have the policies we adopted fit the problem? Have practitioners implemented the policies as intended? (p. 5-6)

While attacking the right problems through asking the right questions is necessary, it is insufficient for solving the problem. The solution requires the application of systematic research practices that produce valid, reproducible, empirically testable, and generalizable results. Yet, educational policies and trends are often based on questionable politically motivated research that claims to find generalizable results, and yet under a closer scrutiny fails to adhere to the rigorous standards of falsifiability, integrity, and scientific skepticism (Hirsch, 2002). This might be due to education being an emerging research field, comprising educators situated on the opposite ends of the research spectrum: from the positivist (examining an objective reality) research that utilizes the natural science methodologies to the purely interpretivist and descriptive research associated with the humanities and social sciences (interpreting a subjective reality). Consequently, modern educational research is abundant with co-existing contradictory "theoretical" frameworks; with the models and pedagogical approaches that can neither be empirically tested nor refuted; with the imprecise if not purposefully overcomplicated language infused with acronyms and vaguely defined terms that cannot be easily understood by practitioners, policymakers or even other researchers (Katz, 1999; Matthews, 2015). Moreover, the scarcity of the studies reporting negative, "politically incorrect" or "inconvenient" results (AERA, 2006) lowers the standards of educational research, making it suffer from what Richard (Feynman, 1974) dubbed the Cargo Cult Science syndrome:

We really ought to look into theories that don't work, and science that isn't science. I think the educational and psychological studies I mentioned are examples of what I would like to call Cargo Cult Science. In the South Seas there is a Cargo Cult of people. During the war they saw airplanes with lots of good materials, and they want the same thing to happen now. So they've arranged to make things like runways, to put fires along the sides of the runways, to make a wooden hut for a man to sit in, with two wooden pieces on his head for headphones and bars of bamboo sticking out like antennas-he's the controller-and they wait for the airplanes to land. They're doing everything right. The form is perfect. It looks exactly the way it looked before. But it doesn't work. No airplanes land. So I call these things Cargo Cult Science, because they follow all the apparent precepts and forms of scientific investigation, but they're missing something essential, because the planes don't land." (p. 11)

In the previous century, researchers have made significant progress in understanding how students learn different STEM subjects and how they can be supported along the way (McDermott, 2001; Bransford et al., 2002; Milner-Bolotin, 2017b). Recently researchers also started a discussion about STEM education as a field vs. educating students in four different subjects (Siekmann, 2016; Siekmann and Korbel, 2016). These researchers questioned why and how is STEM as a whole greater than the sum of its parts, and what is the role of different disciplines in the larger STEM picture (Carnevale et al., 2011; Volmert et al., 2013)? For example, engineering is rarely a separate subject in K-12 education, yet it is often interwoven in students' projects, makerspace labs, and other hands-on activities (Sheridan et al., 2014; Léger and Freiman, 2018). The same can be said about technology in STEM: there is no universal understand of what technology education is, how technology should be integrated with other subjects, and how students should engage with it (Freiman and Tassell, 2018).

As a result of the lack of universal understanding of STEM education as a research field, it is still rife with "research" studies that fall into the Cargo Cult Science category being used to inform educational policies and ongoing reform efforts (Davies, 1999; Matthews, 2015). Thus, it should not be surprising that the "planes don't land" and the reforms that cost the taxpayers millions of dollars keep failing our students (Center for Education Reform, 2018). Fortunately, at the post-secondary level in the STEM education fields, the tide is slowly turning: there is a growing demand of post-secondary institutions to "revise their tenure, promotion, and merit-recognition policies to incentivize and reward implementation of evidence-based instructional practices for all academic ranks" (Stains et al., 2018). There is also a growing number of evidence-based studies that evaluate the effectiveness of different pedagogical approaches at a post-secondary level (Hake, 1998, 2007; Wieman, 2012; Fraser et al., 2014). At the same time, at the K-12 level, we are yet to understand how to support teachers in incorporating evidence-based pedagogies and what is to be considered as evidence that can be used as a base for research-informed policies.

To solve these problems, we have to learn from history: the numerous STEM education reforms of the last 50 years have not brought the intended results, so we have to approach the problem differently (DeBoer, 1991; Dickson, 2001; BSCS, 2008; Let's Talk Science, 2013). It is time to realize that in order to change how students engage with STEM we have to change how we educate K-12 teachers and how we support them during their careers (Schmidt et al., 2011; Niemi et al., 2012). Since in North America a significant number of teachers who teach STEM are not educated in these fields and the majority of elementary teachers have rather limited mathematics and science knowledge, we have to think how to engage all teachers in STEM education (Lawrenz, 1986; 
Ma, 1999; Bursal and Paznokas, 2006; Tobias and Baffert, 2009).

The main argument of this paper is that in order to break the vicious circle of STEM education reform failures, we need to examine and consequently repair the broken link between the evidence-based education research and teacher education practice. Instead of searching for the perfect teacherproof curriculum, assessment or technology, research-based STEM teacher education and professional development should feature prominently in the education reform efforts (NEA, 2010; Blömeke and Delaney, 2012; Center for Education Reform, 2018; Muller, 2018). This is timely, as a new wave of K-12 STEM reforms is engulfing North America and few of them are informed by the evidence-based education research, and even fewer consider teacher education as an integral part of the reform efforts (NRC, 2013; British Columbia Ministry of Education, 2015). In the following section, we suggest how evidencebased STEM education research can become a foundation of STEM teacher education. By STEM teacher education, we mean the education of future secondary mathematics, science, and technology teachers who are open and willing (a) to collaborate with their STEM colleagues, and (b) to promote cross-subject collaboration and inquiry in their teaching (Government of Canada, 2018; Governnment of the UK, 2018; Stains et al., 2018). These are the twenty-first century educators who see STEM education as greater than the sum of its parts and who are ready to promote this view of integrated STEM education in their classrooms. This discussion will be followed by the development of the four-stage approach to teacher education that supports bridging educational research with the teacher education practice.

\section{THEORETICAL BACKGROUND: TEACHER KNOWLEDGE AND EVIDENCE-BASED STEM EDUCATION RESEARCH}

This section describes a theoretical lens used for examining STEM teacher education. Similar to optical lenses utilizing the principles of light propagation, refraction, and dispersion to examine intricate natural phenomena, our theoretical lens is founded on three complementary pillars. First, it uses a constructivist learning theory to examine a formation of teachers' knowledge for teaching STEM (Treagust et al., 2014). Second, it uses Growth Mindset theory to describe the evolution and development of this knowledge (Dweck, 2016). Thirdly, teacher knowledge for teaching STEM will be considered from the perspective of Deliberate Pedagogical Teaching with Technology (Milner-Bolotin, 2016a). This theoretical perspective looks beyond teachers' Technological Pedagogical and Content Knowledge (TPACK) (Koehler and Mishra, 2015). In addition to considering traditional aspects of teachers' knowledge for teaching specific disciplines: teachers' subject matter (content) knowledge, pedagogical approaches for teaching this subject including how the subject is connected to other fields (pedagogical knowledge), or specific educational technologies that can be used in teaching this subject (technological knowledge). Deliberate Pedagogical Thinking with Technology framework looks at how teachers can utilize modern technology to support student collaboration and engagement with specific subjects at a level previously impossible to achieve. For example, many contemporary reform documents call on teachers to implement coherent STEM curricula as opposed to teaching separate subjects (NRC, 2013; British Columbia Ministry of Education, 2015; Levin and Tsybulsky, 2017; Stains et al., 2018). These curricula imply that students will be engaged in collaborative problem solving that crosses the borders of any particular discipline. Solving these problems requires multidisciplinary and interdisciplinary approaches, where the students not only collaborate, but become "experts" in particular sub-fields, while they have to share their expertise with their peers, and often the general public. For example, exploring the contemporary environmental problems, or the implications of the modern power generation, the demographic growth of the Earth's population, the technologies of the future means of transportation and their economic, environmental, and political impact, etc. Modern technologies can enable these explorations not only through providing access to information and outside experts, but also through enabling collaboration at the levels not possible before. These STEM collaborations can happen at multiple time scales-from the short-term collaboration on solving a mathematics or science question, to collaborating during a science lab, to a semester long collaboration on a big STEM project. This will require a very different teacher education, so STEM teachers can view themselves not only as experts in one particular field, but also as educators willing to collaborate with colleagues and ready to grow as teachers beyond their "traditional" education. Here the growth mindset theory (Dweck, 2016) becomes especially valuable.

The growth mindset theory studies what helps people to persevere in the face of failure. One of the key findings of the theory is that what matters most are people's beliefs about learning and intelligence. The people who believe in the capacity to grow, to acquire new skills and knowledge are much stronger in the face of temporary failure. These people are less likely to give up in the face of failure, moreover, they often see failure as a nature thing on the way to success (Milner-Bolotin, 2018a). This applies to students, as well as to teachers, who are continuously challenged with learning new pedagogical approaches, new content, and new technologies. This is especially relevant to the education systems with a lot of high-stake assessments, where failure is often considered to be fatal (Ripley, 2013).

The constructivism, the growth mindset theory, and Deliberate Pedagogical Thinking with Technology will be applied to designing learning environments in STEM teacher education conducive to the formation and growth of STEM teacher knowledge and teacher-candidates' positive attitudes about learning. The combination of these theoretical pillars is important as they take into account not only the current state of teacher knowledge, but the potential for its growth through technology-enhanced collaboration, while emphasizing the value of teachers' attitudes and beliefs about learning (Milner-Bolotin, 2017b). Through focusing on the growth of STEM teacher knowledge during teacher education, we will attempt to discern 
previously invisible details and uncover the untapped potential of evidence-based education research for STEM teacher education practice.

\section{Growth of Teacher Knowledge}

Education and its role in society have been the focus of philosophical inquiry for centuries. Lately, researchers focused on the development of teacher knowledge and skills, as well as teachers' beliefs and attitudes about learning. The Pedagogical Content Knowledge (PCK) framework proposed by Shulman (1986) challenged the assumption that Content Knowledge (CK) and Pedagogical Knowledge (PK) are mutually exclusive facets of knowledge for teaching. By emphasizing the overlap of these fields (PCK) and its role in effective teaching, Shulman attempted to define teaching as a profession that requires a highly specialized knowledge (Tobias and Baffert, 2009). The PCK framework has been adopted and adapted by other researchers who explored different facets of teacher knowledge. Some examined the development of teachers' Content Knowledge (CK) (Ball et al., 2008). Other researchers focused on the role of technology and expanded PCK into the Technological Pedagogical and Content Knowledge (TPACK) framework (Mishra and Koehler, 2006), while others investigated the development of teachers' attitudes and openness toward using inquiry, active engagement, and innovative research-based pedagogies (Blömeke and Delaney, 2012; Auerbach et al., 2018).

In our recent work we focused on the development of teachers' ability to use technology deliberately to promote student collaboration, active engagement and conceptual learning beyond what was possible earlier (Milner-Bolotin, 2016a). We emphasized that it is not only important that teachers learn how to use educational technology for teaching a specific subject (TPACK), but to learn how to use it to promote a different kind of student collaborative engagement with the subject's content. This is especially important for teaching STEM as a unified concept. For example, Peer Instruction and PeerWise allow the implementation of question-driven collaborative pedagogy that would have been impossible before the invention of these technologies (Milner-Bolotin et al., 2016). However, while these tools are freely available, without teachers' knowledge about how to use them and teachers' motivation to use these tools deliberately to promote student learning, these technologies will remain underused if not misused tools (Cuban, 2001; MilnerBolotin et al., 2010; MacArthur et al., 2011).

As it was mentioned above, psychologists have been exploring the value of attitudes about learning (the growth mindset) for understanding why some learners succeed in the face of failure while others don't (Dweck, 2016). The growth mindset also applies to teachers and the growth of their own knowledge for teaching, as well as their ability and willingness to incorporate innovative research-based pedagogies. As any teacher can attest, teaching often means persevering through failures and not giving up. This is especially relevant to teaching with technology, where an educators needs not only to learn how this technology functions, but also how to use it to benefit students.

At the core of these frameworks is the understanding that teacher knowledge is a complex dynamic construct whose growth is affected by the teachers' initial CK, learning experiences, attitudes about learning, views about teaching as a profession, their practice, and opportunities for professional development, reflection, and peer collaboration. The formation of teacher knowledge neither begins nor ends in teacher education, but it is shaped by it. Thus, it is important to examine available research evidence on the growth of teacher knowledge during teacher education and consider how it might inform STEM teacher educators.

\section{What Is Evidence-Based STEM Education Research?}

According to Davies (1999), the goal of evidence-based education research is to pose answerable questions about education, to answer them using professional and scientific research standards, and to share these findings with the wider community. At the core of this definition are the terms answerable questions and scientific research standards. Thus, evidence-based education research findings must be scrutinized, subjected to critical analysis according to research standards and accepted research methods, verified in multiple contexts, and when needed, challenged, or refuted.

Davies suggests that evidence-based educational research can be conducted at two levels: at the first one, the researchers utilize already existing evidence to answer their questions. At the second level, they plan, carry out, and disseminate original research that generates new evidence to help answer the research questions, suggest and test competitive analyses and interpretations of the data, propose testable competing theories, challenge widely accepted assumptions, and ask new questions. At both levels, practitioners of evidence-based education research build their studies on the available literature; incorporate the methods of the social and natural sciences, the humanistic and interpretive disciplines to produce cumulative research that adheres to the highest research standards. This can only be achieved if "future research on education meets the criteria of scientific validity, high-quality, and practical relevance that is sometimes lacking in existing evidence on educational activities, processes, and outcomes" (Davies, 1999). Most importantly, the evidence collected by the researchers should warrant the conclusions and implications of the research and be sufficient to refute alternative interpretations.

Evidence-based education research aims at advancing our knowledge of educational issues to inform both policy and practice. It is especially suitable for examining STEM learning, as STEM fields are the birthplace of scientific method (Kuhn, 1996). As a result, the call for evidence-based education research has been welcomed by many STEM educators (Wieman and Perkins, 2005; Handelsman et al., 2007; Wieman, 2012; Fraser et al., 2014). In the following section, we examine the role of evidence-based education research in STEM teacher education.

\section{DISCUSSION: EVIDENCE-BASED RESEARCH AS A FOUNDATION OF STEM TEACHER EDUCATION}

This section highlights one area where repairing the broken link between evidence-based STEM education research and 
teacher education practice might be especially beneficial. We consider how education research can support the development of STEM teacher-candidates' knowledge for teaching, their growth mindset, and positive attitudes about the role of research in their teaching practice.

\section{Repairing the Research-Practice Link: Evidence-Based Research and STEM Teacher Education}

Evidence-based STEM education research has a longstanding tradition (Levin and Tsybulsky, 2017; Miller et al., 2017; Stains et al., 2018). For example, student conceptual understanding in different individual STEM fields (e.g., physics, chemistry, biology) has been extensively studied, but this research is yet to be fully incorporated into STEM teacher education (McDermott et al., 2006). One reason for that is a separation of STEM (B.Sc.) and education (B.Ed.) degrees and a consequent decoupling of the content-focused and pedagogically-geared courses. For example, in Canada STEM teacher-candidates first earn a relevant B.Sc. degree and then depending on the province complete a 1- or 2-year long teacher education program (MilnerBolotin, 2014). While concurrent teacher education happens, it is not a common practice. Due to their limited duration, teacher education programs usually have little time to devote to the development of teacher-candidates' CK and consequently their PCK (Shulman, 1986). Therefore, these programs have to assume, that teacher-candidates have already mastered the necessary CK and only need to develop their PK. However, ample research evidence suggests that this is not the case (Ma, 1999; Milner-Bolotin et al., 2013; Campbell et al., 2014; Zazkis and Kontorovich, 2016). Therefore, not devoting enough time to helping teacher-candidates revisit their $\mathrm{CK}$ and connect it to the relevant $\mathrm{PK}$ becomes problematic.

The same applies to general pedagogical courses aimed at promoting active learning, formative assessment, inquiry, or technology-enhanced pedagogies. For example, there is ample research evidence that active engagement is important for STEM learning (Hake, 1998; Crouch and Mazur, 2001). However, in order to enact it in STEM classrooms, teachers have to acquire very specific skills, such as an ability to design and facilitate inquiry-driven activities, to use STEM-specific educational technologies, to implement inquiry-based labs and projects (Milner-Bolotin, 2004, 2012). In order to do that, teachers have to possess the necessary TPACK, to understand how and why these activities facilitate learning (the research evidence), and experience these learning environments first as learners and then to reflect on these experiences as future teachers (Milner-Bolotin et al., 2013, 2016).

Repairing the research-practice link in this context means that STEM teacher education should be informed by STEM education research (Milner-Bolotin, 2018b). Only after teachercandidates have multiple opportunities to challenge their own STEM understanding, TPACK, and reflect on how one learns STEM, they will be open and capable to enact research-based pedagogies in their own classrooms (MilnerBolotin, 2016b). Since few STEM teacher-candidates have experienced research-based pedagogies in their own education, this has to be done during teacher education (MilnerBolotin, 2017b). Moreover, evidence-based research should apply to STEM teacher education itself. Teacher educators should lead by example by continuously collecting and analyzing evidence on the pedagogical effectiveness of their own courses, the growth of teacher-candidates' TPACK, and teachercandidates' attitudes about learning and the role of research in teaching.

\section{From Theory to Practice: Incorporating Research-Based Pedagogies in STEM Teacher Education}

In this section, we suggest a pedagogical approach for incorporating research-based pedagogies into teacher education practice and illustrate how it was used in the context of STEM teacher education. This approach has four stages: (a) Model: Teacher-candidates experience research-based pedagogy; (b) Reflect: They reflect on their experiences as learners and as future teachers; (c) Research: They discuss the research foundation of this pedagogy; (d) Practice: They practice incorporating this pedagogy in their own teaching. The Model-Reflect-ResearchPractice approach was designed to engage teacher-candidates with novel pedagogies as students and as future teachers and acquire positive attitudes about the value of evidence-based education research in their own practice. Below we describe two examples of how this approach was implemented in a STEM teacher education practice and how modern educational technologies were used in this process.

\section{Active Engagement With PeerWise and Peer Instruction}

As mentioned above, there is ample evidence that active engagement is crucial for STEM learning (Hake, 1998). To support teacher-candidates in adopting active engagement in their own teaching, in STEM methods courses we incorporated Peer Instruction (Mazur, 1997) that used a classroom response system (clickers) (Milner-Bolotin, 2016b). We used the four-step approach discussed above:

(a) Model: Peer Instruction was modeled in the methods courses, such as teacher-candidates experienced it as students. They were presented with a conceptual multiple-choice STEM question asked by the instructor. They answered this question individually using clickers, then the aggregated histogram of their responses was shown on the board. Then teachercandidates were asked to discuss their responses with peers. Finally, they answered the same question individually one more time. The all class discussion followed the display of the final response histogram.

(b) Reflect: Teacher-candidates discussed their learning experience. They reflected on the question, the purpose of the distractors, and the STEM concept targeted by the question. They also reflected on their own $\mathrm{CK}$, the experience of peer discussions, the instructor's behavior and PCK needed to facilitate student active engagement. 
(c) Research: As a follow up, the instructor facilitated a discussion on active engagement in STEM learning, how it can be enacted, and evaluated. It was based on carefully chosen evidence-based research (Fagen et al., 2002; Lasry, 2008). The instructor brought up the evidence-based research on conceptual STEM understanding, common misconceptions and the importance of prior knowledge (Bransford et al., 2002). The instructor also emphasized the importance of deliberate pedagogical thinking with technology as opposed to using technology for its own sake (Milner-Bolotin, 2016a).

(d) Practice: In order to facilitate the growth of teachercandidates' TPACK and their confidence with Peer Instruction, we also incorporated a PeerWise online collaborative tool (Milner-Bolotin et al., 2016). PeerWise allowed teacher-candidates to collaborate on designing effective conceptual multiple-choice questions, respond to the questions designed by their peers, and provide constructive feedback to each other. This was followed up by teachercandidates using these questions in their own classrooms during the school practicum.

\section{Reflection as a Catalyst for Teacher Growth}

In order to support teacher-candidates in developing their growth mindset, we used a Collaborative Learning Annotation System (CLAS) (Milner-Bolotin, 2018b). CLAS is an online platform that allows uploading and storing of videos, as well as providing time-specific video annotation and collaboration. The comments can be anonymous or not and can be visible to the entire group or only to specific participants. The participants can also initiate a discussion focused on specific comments or parts of the video.

(a) Model: During STEM methods courses, teacher-candidates video recorded their micro-teaching sessions (12-15 min long) and uploaded them on CLAS. In a micro-teaching session, teacher-candidates were asked to teach a mini-lesson to 3-5 of their peers. These mini-lessons focused on specific STEM concepts, pedagogy, and educational technology.

(b) Reflect: As a homework assignment, teacher-candidates watched their peers' mini-lessons and provided constructive feedback to each other. They also responded to their peers' feedback and reflected on how they could address the feedback in their next mini-lesson.

(c) Research: After teacher-candidates had experienced microteaching and CLAS collaboration they were presented with the research on the role of reflection on STEM teacher growth (Etkina, 2000). Reflecting on the growth of teacher knowledge and on their personal growth was an important part of this activity. Moreover, since each teacher-candidate had at least four recorded mini-lessons, it was a great opportunity to discuss the value of the growth mindset for their own personal development (Dweck, 2016).

(d) Practice: Finally, reflection and growth mindset were practiced by teacher-candidates during their 10-week long school practicum. In the practicum, they had to teach STEM lessons and were continuously observed by experienced educators who helped teacher-candidates to reflect on their teaching. Thus, incorporating CLAS into STEM methods courses helped prepare teacher-candidates for a successful school practicum experience.

\section{Evaluation of the Implementation of These Research-Based Pedagogies}

The two examples discussed above show how evidence-based education research can be incorporated into STEM teacher education. We have published the results of this implementation elsewhere (Milner-Bolotin et al., 2013, 2016; Milner-Bolotin, 2017a). The results indicate that these pedagogical approaches promotes the growth of teacher-candidates' knowledge for STEM teaching, their openness to collaborate with peers and to learn from each other. Moreover, teacher-candidates not only expanded their TPACK, but also learned how to use technology deliberately to promote student learning. They were able to demonstrate their confidence, TPACK, and their ability to engage students in STEM learning during their school practicum that followed the methods course.

While these two examples are different, they have a common theme: research evidence on how students learn STEM, how teacher knowledge grows and how teachers acquire growth mindset, were became a foundation of teacher education practice. Moreover, both examples show that teachercandidates had multiple opportunities to experience researchbased pedagogies, reflect on these experiences, appreciate the research underlying these pedagogies, and had multiple opportunities to implement these pedagogies in their own practice.

\section{CONCLUSIONS AND IMPLICATIONS FOR PRACTICE}

In the world heavily shaped by technology, many countries face significant challenges in engaging their students in meaningful STEM learning (OECD, 2016). This is reflected not only in inadequate student performance on the international mathematics and science assessments, such as PISA, but also in their growing STEM disengagement (Let's Talk Science, 2013, 2017). While educators and policy makers have been trying to address this problem for decades, it has become clear that their approaches have failed to bring the intended outcomes (Cuban, 1990; Feder, 2010).

In order to address this problem, educators need to repair the broken link between the evidence-based STEM education research, educational policy, and practice. This paper suggests a four-step approach relevant to STEM teacher education that addresses this problem: Model-Reflect-ResearchPractice. This approach is especially relevant to educating STEM teachers. Since STEM teachers are often educated as science, mathematics, or technology teachers, they rarely have an opportunity to experience truly multidisciplinary and interdisciplinary STEM education, collaborate with peers who have different STEM backgrounds or use technology to 
engage in STEM education (Martinovic, 2011). Moreover, the research on educating STEM teachers, as opposed to science, mathematics and technology teachers is also in its infancy.

We should support researchers in conducting evidencebased STEM education research that produces reliable and generalizable results that can inform educational policy and empower practitioners. Evidence-based education research should become a foundation of STEM teacher education to allow educators to learn from the past and to affect the future. This is especially relevant for STEM teacher education. Teacher-candidates should have an opportunity to experience the value of education research for their own teaching practice and engage in designing and implementing research-based pedagogies. This paper has shown two examples of how it can be done in STEM teacher education and how modern educational technologies can aid in this process. However, more evidence-based research needs to be conducted to investigate the impact of these pedagogies on teacher-candidates and their personal growth. The time has come to learn from the history of STEM education reform failures in order to break this vicious circle. We call on STEM education researchers and teacher educators to incorporate evidence-based research into teacher education practice, to measure the pedagogical effectiveness of their pedagogical innovations, and share these results with the larger community.

\section{REFERENCES}

AERA (2006). Standards for reporting on empirical social science research in AERA publications. Edu Res. 35, 33-40. doi: 10.3102/0013189X0350 06033

Auerbach, A. J., Higgins, M., Brickman, P., Andrews, T. C., and Labov, J. (2018). Teacher knowledge for active-learning instruction: Expert-novice comparison reveals differences. CBE-Life Sci. Edu. 17:ar12. doi: 10.1187/cbe.17-0 7-0149

Ball, D. L., Thames, M. H., and Phelps, G. (2008). Content knowledge for teaching: What makes it special? J. Teacher Edu. 59:389. doi: 10.1177/00224871083 24554

Blömeke, S., and Delaney, S. (2012). Assessment of teacher knowledge across countries: a review of the state of research. ZDM Mathemat. Edu. 44, 223-247. doi: 10.1007/s11858-012-0429-7

Bransford, J. D., Brown, A. L., and Cocking, R. R. (2002). How People Learn: Brain, Mind, Experience, and School. Washington, DC: The National Academies Press.

British Columbia Ministry of Education (2015). Building Students Success: BC's New Curriculum [Online]. Victoria, BC: BC Ministry of Education, Available online at: https://curriculum.gov.bc.ca/ (Accessed October 17, 2018).

BSCS (2008). Scientists in Science Education: 1958-2008 Innovation Reform Vision. Colorado Springs, CO. Available online at: www.bscs.org (Accessed October 17, 2018).

Bursal, M., and Paznokas, L. (2006). Mathematics anxiety and preservice elementary teachers' confidence to teach mathematics and science. School Sci. Mathemat. 106, 173-180. doi: 10.2307/749455

Campbell, P. F., Nishio, M., Smith, T. M., Clark, L. M., Conant, D. L., Rust, A. H., et al. (2014). The relationship between teachers' Mathematical Content and Pedagogical Knowledge, teachers' perceptions, and student achievement. J. Res. Mathemat. Edu. 45, 419-459. doi: 10.5951/jresematheduc.45.4.041

Carnevale, A. P., Smith, N., and Melton, M. (2011). STEM: Science Technology Engineering Mathematics. State-Level Analysis. Washington, DC: Georgetown University Center on Education and the Workforce.

\section{ETHICS STATEMENT}

This study was carried out in accordance with the recommendations of the University of British Columbia Research Ethics Board, [Human Ethics Committee]. The protocol was approved by the UBC Research Ethics Board. All subjects gave written informed consent in accordance with the Declaration of Helsinki.

\section{AUTHOR CONTRIBUTIONS}

The author confirms being the sole contributor of this work and has approved it for publication.

\section{FUNDING}

This research was supported by the Advanced Innovation Centre for Future Education, Beijing Normal University, Beijing, China and by the University of British Columbia Teaching and Learning Enhancement Fund.

\section{ACKNOWLEDGMENTS}

The author would like to acknowledge Advanced Innovation Centre for Future Education, Beijing Normal University, Beijing, China for their support in this study.

Center for Education Reform (2018). A Nation Still at Risk? Results from the Latest NAEP Recall the Report from 35 Years Ago. Available online at: https://www. edreform.com/2018/04/a-nation-still-at-risk/ (Accessed October 17, 2018).

Crouch, C. H., and Mazur, E. (2001). Peer instruction: ten years of experience and results. Am. J. Phys. 69, 970-977. doi: 10.1119/1.1374249

Cuban, L. (1990). Reforming again, again, and again. Edu. Res. 19, 3-13. doi: 10.3102/0013189X019001003

Cuban, L. (2001). Oversold and Underused: Computers in the Classroom. Cambridge, MA: Harvard University Press.

Davies, P. (1999). What is evidence-based education? Br. J. Edu. Stud. 47, 108-121. doi: 10.1111/1467-8527.00106

DeBoer, G. E. (1991). A History of Ideas in Science Education: Implications for Practice. New York, NY; London: Teachers College Press.

Dickson, P. (2001). Sputnik: The Shock of the Century. New York, NY: Walker Publishing Company.

Dweck, C. S. (2016). Mindset: The New Psychology of Success. New York, NY: Penguin Random House LLC.

Etkina, E. (2000). Weekly reports: a two-way feedback tool. Sci. Edu. 84, 594-605. doi: 10.1002/1098-237X(200009)84:5<594::AID-SCE3>3.0.CO;2-U

Fagen, A. P., Crouch, C. H., and Mazur, E. (2002). Peer instruction: results from a range of classrooms. Phys. Teacher 40, 206-209. doi: 10.1119/1.1474140

Feder, T. (2010). Europe reflects on a decade of higher education reforms. Phys. Today 63, 24-27. doi: 10.1063/1.3431323.

Feynman, R. P. (1974). Cargo Cult Science: some remarks on science, pseudoscience, and learning how to not fool yourself. Caltech's 1974 Commencement Address. Eng. Sci. 37. 10-13.

Fraser, J. M., Timan, A. L., Miller, K., Dowd, J. E., Tucker, L., and Mazur, E. (2014). Teaching and physics education research: bridging the gap. Rep. Progress Phys. 77:17. doi: 10.1088/0034-4885/77/3/032401

Freiman, V., and Tassell, J. L. (2018). "Leveraging mathematics creativity by using technology: questions, issues, solutions, and innovative paths," in Creativity and Technology in Mathematics Education, eds V. Freiman and J. Tassel (Cham: Springer), 3-29. 
Government of Canada (2018). The Government of Canada and STEM. Ottawa, ON: Government of Canada. Available online at: https://www.ic.gc.ca/eic/site/ 013.nsf/eng/00014.html (Accessed).

Governnment of the UK (2018). STEM Strategy. UKDO Education (London).

Hake, R. R. (1998). Interactive-engagement versus traditional methods: a sixthousand-student survey of mechanics test data for introductory physics courses. Am. J. Phys. 66, 64-74. doi: 10.1119/1.18809

Hake, R. R. (2007). Six lessons from the physics education reform effort. Latin-Am. J. Phys. Edu. 1, 24-31.

Handelsman, J., Miller, S., and Pfund, C. (2007). Scientific Teaching. (New York, NY: W.H. Freeman \& Company), 47-64.

Hirsch, E. D. (2002). Classroom Research and Cargo Cults. Policy Review: Hoover Institution October-November.

Katz, S. (1999). How to speak and write post-modern. English Acad. Rev. 16, 88-91. doi: 10.1080/10131752.1999.10384455

Koehler, M. J., and Mishra, P. (2015). "Technological pedagogical content knowledge," in The SAGE encyclopedia of Educational Technology, ed M. J. Spector (Los Angeles, CA: SAGE Publications), $782-785$.

Kuhn, T. (1996). The Structure of Scientific Revolutions. Chicago, IL: University of Chicago Press. doi: 10.7208/chicago/9780226458106.00 1.0001

Lasry, N. (2008). Clickers or flashcards: is there really a difference? Phys. Teacher 46, 242-244. doi: 10.1119/1.2895678

Lawrenz, F. (1986). Misconceptions of physical concepts among elementary school teachers. School Sci. Mathemat. 86, 654-660. doi: 10.1111/j.1949-8594.1986.tb11669.x

Léger, M. T., and Freiman, V. (2018). "Learning to be creative: a causalcomparative study of digital skill development in a technology-rich classroom," in American Educational Research Association Annual Meeting (New York, NY: AERA). Available online at: http://www.aera.net/Publications/Online-PaperRepository/AERA-Online-Paper-Repository

Let's Talk Science (2013). Spotlight on Science Learning: The High Cost of Dropping Science and Math. Toronto, ON: Let's Talk Science.

Let's Talk Science (2017). Canada-2067: The Science of a Successfull Tomorrow. Ottawa, ON: Let's Talk Science. Available online at: https://canada2067.ca/en/ (Accessed April, 4 2017).

Levin, I., and Tsybulsky, D. (2017). Digital Tools and Solutions for Inquiry-Based STEM Learning. Hershey, PA: IGI Global. doi: 10.4018/978-1-5225-2525-7

Ma, L. (1999). Knowing and Teaching Elementary Mathematics: Teachers' Understanding of Fundamental Mathematics in China and in the United States. Mahwah, NJ: Lawrence Erlbaum Associates.

MacArthur, J., Jones, L., and Suits, J. (2011). Faculty viewpoints on teaching largeenrollment science courses with clickers. J. Comp. Mathemat. Sci. Teach. 30, 251-270. Available online at: https://eric.ed.gov/?id=EJ943448

Martinovic, D. (2011). "Online video technology as enabler for teaching and learning multidisciplinary topics," in Interdisciplinarity for the 21st Century; The Montana Mathematics Enthusiast Monographs in Mathematics Education, eds B. Sriraman and V. Freiman (Charlotte, NC: Information Age Publishing), 309-326.

Matthews, M. R. (2015). Reflections on 25 years of journal editorship. Sci. Edu. 24, 749-805. doi: 10.1007/s11191-015-9764-8

Mazur, E. (1997). "Peer Instruction: Getting students to think in class," in Paper presented at the Changing Role of Physics Departments in Modern Universities: Part Two: Sample Classes. College Park, MD: University of Maryland.

McDermott, L. C. (2001). Oersted medal lecture 2001: physics education research: the key to student learning. Am. J. Phys. 69, 1127-1137. doi: 10.1119/1.13 89280

McDermott, L. C., Heron, P. R. L., Shaffer, P. S., and Stetzer, M. R. (2006). Improving the preparation of K-12 teachers through physics education research. Am. J. Phys. 74, 763-767. doi: 10.1119/1.2209244

Miller, E. R., Fairweather, J. S., Slakey, L., Smith, T., and King, T. (2017). Catalyzing institutional transformation: insights from the AAU STEM Initiative. Change 49, 36-45. doi: 10.1080/00091383.2017.13 66810

Milner-Bolotin, M. (2004). Tips for using a peer response system in the large introductory physics classroom. Phys. Teacher 42, 253-254. doi: 10.1119/1.16 96604
Milner-Bolotin, M. (2012). Increasing interactivity and authenticity of chemistry instruction through data acquisition systems and other technologies. J. Chem. Edu. 89, 477-481. doi: 10.1021/ed10 08443

Milner-Bolotin, M. (2014). Promoting research-based physics teacher education in Canada: building bridges between theory and practice. Phys. Canada 70, 99-101. Available online at: https:/pic-pac.cap.ca/static/downloads/ 5736d7fb5ed6b8a37319bfd816600c404da40bc1.pdf

Milner-Bolotin, M. (2016a). "Promoting deliberate pedagogical thinking with technology in physics teacher education: a teacher-educator's journey," in The Physics Educator: Tacit Praxes and Untold Stories eds. T. G. Ryan and K. A. McLeod (Champaign, IL: Common Ground and The Learner), 112-141.

Milner-Bolotin, M. (2016b). Rethinking technology-enhanced physics teacher education: from theory to practice. Can. J. Sci. Mathemat. Technol. Edu. 16, 284-295. doi: 10.1080/14926156.2015.1119334

Milner-Bolotin, M. (2017a). "Modeling PeerWise and CLAS technologies in secondary physics teacher education," in American Association of Phyiscs Teachers Winter 2017 Meeting, ed G. Ramsey (Atlanta, GA: AIP). Available online at: https://www.aapt.org/Conferences/WM2017/upload/ program_online.pdf

Milner-Bolotin, M. (2017b). "Technology-supported inquiry in STEM teacher education: Collaboration, challenges and possibilities," in Digital Tools and Solutions for Inquiry-Based STEM Learning, eds I. Levin and D. Tsybulsky (Hershey, PA: IGI Global), 252-281.

Milner-Bolotin, M. (2018a). "Nurturing creativity in future mathematics teachers through embracing technology and failure," in Creativity and Technology in Math Education, eds V. Freiman and J. Tassell (Cham: Springer), 251-278.

Milner-Bolotin, M. (2018b). Promoting reflective physics teaching through the use of collaborative learning annotation system. Phys. Teacher 56, 313-316. doi: $10.1119 / 1.5033879$

Milner-Bolotin, M., Antimirova, T., and Petrov, A. (2010). Clickers beyond the first year science classroom. J. College Sci. Teaching 40, 18-22. Available online at: https://eric.ed.gov/?id=EJ921505

Milner-Bolotin, M., Egersdorfer, D., and Vinayagam, M. (2016). Investigating the effect of question-driven pedagogy on the development of physics teachercandidates' pedagogical content knowledge. Phys. Rev. Special Top. 12, 1-16. doi: 10.1103/PhysRevPhysEducRes.12.020128

Milner-Bolotin, M., Fisher, H., and MacDonald, A. (2013). Modeling active engagement pedagogy through classroom response systems in a physics teacher education course. LUMAT Int. J. Math, Sci. Technol. Edu. 1, 523-542. Available online at: https://www.lumat.fi/index.php/lumat-old/article/view/159

Mishra, P., and Koehler, M. J. (2006). Technological pedagogical content knowledge: a framework for teacher knowledge. Teachers College Rec. 108, 1017-1054. doi: 10.1111/j.1467-9620.2006.00684.x

Muller, D. (2018). This Will Revolutionize Education. Available online at: https://www.youtube.com/watch?v=GEmuEWjHr5c (Accessed October 17, 2018).

NEA (2010). Teacher Assessment and Evaluation: The National Education Association's Framework for Transforming Education Systems to Support Effective Teaching and Improve Student Learning. National Education Association: Washington, DC.

Niemi, H., Toom, A., and Kallioniemi, A. (eds.). (2012). Miracle of Education. New York, NY: Sense Publishing. Available online at: https://www.sensepublishers. com/media/655-miracle- of-education.pdf

NRC (2013). Next Generation Science Standards: For States, by States. Washington DC: The National Academies Press, USA National Research Council.

OECD (2016). PISA 2015 Results in Focus. Paris: OECD Publishing.

Ripley, A. (2013). The Smartest Kids in the World: And How They Got That Way. New York, NY: Simon and Schuster.

Schmidt, W. H., Blömeke, S., Tatto, M. T., Hsieh, F.-J., Cogan, L. S., Houang, R. T., et al. (2011). Teacher Education Matters: A Study of Middle School Mathematics Teacher Preparation in Six Countries. New York, NY: Teachers College Press.

Sheridan, K., Halverson, E. R., Litts, B., Brahms, L., Jacobs-Priebe, L., and Owens, T. (2014). Learning in the making: a comparative case study of three makerspaces. Harvard Edu. Rev. 84, 505-531. doi: 10.17763/haer.84.4.brr34733723 j648u 
Shulman, L. S. (1986). Those who understand: knowledge growth in teaching. $E d u$. Res. 15, 4-14. doi: 10.3102/0013189X015002004

Siekmann, G. (2016). What is STEM? The Need for Unpacking its Definitions and Applications (Adelaide, SA: NSVER).

Siekmann, G., and Korbel, P. (2016). Defining 'STEM' Skills: Review and Synthesis of the Literature-Support Document 1 NCVER. NCVER.

Stains, M., Harshman, J., Barker, M. K., Chasteen, S. V., Cole, R., DeChenne-Peters, S. E., et al. (2018). Anatomy of STEM teaching in North American universities. Science 359, 1468-1470. doi: 10.1126/science.aap8892.

Tobias, S., and Baffert, A. (2009). Science Teaching as a Profession: Why It Isn't How It Could Be. Tucson, AZ: Research Corporation for Science Advancement.

Treagust, D. F., Won, M., and Duit, R. (2014). "Paradigms in science education research," in Handbook of Research on Science Education, eds L. G. Norman and S. K. Abell (New York, NY: Routledge), 3-17.

Volmert, A., Baran, M., Kendall-Taylor, N., and O’Neil, M. (2013). "You have to have the basics down really well," in Mapping the Gaps Between Expert and Public Understanding of STEM Learning (Washington, DC: FrameWorks Institute). Available online at: https://sites.nationalacademies.org/cs/groups/ dbassesite/documents/webpage/dbasse_088203.pdf
Wieman, C. E. (2012). Applying new research to improve science education. Issues Sci. Technol. 29, 1-9. Available online at: https://issues.org/carl/

Wieman, C. E., and Perkins, K. (2005). Transforming physics education Phys. Today 58, 36-42. doi: 10.1063/1.2155756

Zazkis, R., and Kontorovich, I. (2016). A curious case of superscript (-1): Prospective secondary mathematics teachers explain. J. Mathemat. Behav. 43, 98-110. doi: 10.1016/j.jmathb.2016.07.001

Conflict of Interest Statement: The author declares that the research was conducted in the absence of any commercial or financial relationships that could be construed as a potential conflict of interest.

Copyright (C) 2018 Milner-Bolotin. This is an open-access article distributed under the terms of the Creative Commons Attribution License (CC BY). The use, distribution or reproduction in other forums is permitted, provided the original author(s) and the copyright owner(s) are credited and that the original publication in this journal is cited, in accordance with accepted academic practice. No use, distribution or reproduction is permitted which does not comply with these terms. 